\title{
Gonadal function in young adults after surgical treatment of cryptorchidism
}

\author{
E A WERDER, R ILLIG, T TORRESANI, M ZACHMANN, P BAUMANN, F OTT, A PRADER
}

British Medical fournal, 1976, 2, 1357-1359

\section{Summary}

In a follow-up study of 48 young men who had been surgically treated for cryptorchidism before puberty testicular function was assessed by examining the genitalia, testicular volume, secondary sex characteristics, semen, plasma luteinising hormone (LH) and follicle-stimulating hormone (FSH) concentrations after luteinising hormone-releasing hormone stimulation, and plasma testosterone concentrations.

Clinical androgen effects were normal. The mean testicular volume of both testes was in the low normal range in those who had had unilateral cryptorchidism and below normal in those who had had bilateral cryptorchidism. Of 37 patients whose sperm counts were recorded (14 bilateral) six showed azoospermia (all bilateral), five had severe oligospermia (four bilateral), and 10 had moderate oligospermia (one bilateral). In nearly all those who had had bilateral cryptorchidism and most of those who had had unilateral cryptorchidism plasma gonadotrophin levels were increased. Four cases of possible partial LH deficiency were identified. Plasma testosterone concentrations were normal in all except two patients.

\section{Introduction}

Several studies have shown a high incidence of infertility in men who had been operated on during childhood for bilateral cryptorchidism..$^{1-5}$ In most of these patients surgical treatment was performed late in childhood. Infertility may therefore have resulted from the damaging effect of raised temperatures, to which the testes had been exposed for longer periods, or it may have been due to a primary testicular defect, since histological defects have also been observed in the descended contralateral testes of patients with unilateral cryptorchidism. ${ }^{6}$ 7

In an effort to clarify pathogenic mechanisms we studied the hypothalamo-pituitary-gonadal axis in 48 young men who had been surgically treated for cryptorchidism in childhood.

\section{Patient and methods}

Forty-eight healthy men of normal stature without additional malformations, infections, or trauma of the genitalia and testes were included in the follow-up study. Forty-one were recruited by a letter sent to 81 patients who had been operated on in 1960-1 at the depart-

Department of Paediatrics, University of Zurich, Switzerland E A WERDER, MD, research fellow R ILLIG, MD, physician

T TORRESANI, LIC CHEM, chemist

M ZACHMANN, MD, physician

A PRADER, MD, professor

Department of Dermatology, University of Zurich, Switzerland P BAUMANN, MD, physician

F OTT, MD, professor ment of paediatric surgery, University of Zurich. The mean age of the group was 24 years (range 16-27 years). Sixteen had been operated on for bilateral and 32 for unilateral cryptorchidism. In all surgery had been performed before the onset of puberty, at a mean age of 11 years (range 5-17 years). At surgery the testes had been placed into the opposite half of the scrotum according to Ombrédanne's method. Before surgery 11 patients had been unsuccessfully treated with human chorionic gonadotrophin.

Physical examination included an assessment of the genitalia, testicular volume, ${ }^{8}$ and secondary sex characteristics. Thirty-seven patients provided specimens for semen analysis after five days of sexual abstinence. Immediately after ejaculation the morphology, motility, and the number of sperms were evaluated by an experienced technician.

The luteinising hormone-releasing hormone (LH-RH) test was performed by intravenous injections of LH-RH (Hoechst) $25 \mathrm{\mu g} / \mathrm{m}^{2}$ of body surface area. No untoward reactions were observed. Blood samples were taken through an indwelling cannula inserted into an arm vein $0,10,20,30,60$, and 120 minutes after injection. The heparinised blood was centrifuged at $4^{\circ} \mathrm{C}$, and the plasma was stored at $-16^{\circ} \mathrm{C}$ until analysed. Luteinising hormone (LH) and folliclestimulating hormone (FSH) levels were determined radioimmunologically with a double antibody method using reagents provided by the NIAMDD, Bethesda, Maryland, USA. The results were expressed as $\mathrm{ng} / \mathrm{ml}$ of LER 907 standard.

Thirteen healthy young men ranging in age from 25 to 35 years served as controls. Since maximum values of $\mathrm{LH}$ and FSH after stimulation provide the best distinction between normal and pathological results, peak values only are presented. Blood samples for determining basal testosterone concentrations were taken at about $9 \mathrm{am}$, immediately before LH-RH stimulation. Basal plasma testosterone was measured by radioimmunoassay using a specific antibody which cross-reacts significantly only with dihydrotestosterone. Informed consent was obtained from all the men studied.

\section{Results}

The development of the genitalia, the secondary sex characteristics, and sexual activity were normal in most patients. In two cases sexual drive seemed to be diminished. Seven men had been married for up to three years, but only one of them (who had had unilateral cryptorchidism) was a father. Both testes were in the scrotum in all except one patient, where only one testis was palpable. The testicular volume measurements are shown in table I and the figure. In the 32 patients who had been unilaterally cryptorchid before operation the mean volume of the formerly cryptorchid testes as well as that of the scrotal testes were significantly $(P<0.001$ and $P<0.05$ respectively) smaller than normal, though the mean volume of both testes in individual patients was within the normal range (see figure). In the 16 patients who had been bilaterally cryptorchid the mean volume of both testes was significantly $(P<0.001)$ smaller than normal.

The results of the sperm counts performed in 37 cases are shown in the figure. Of the 23 patients who had been unilaterally cryptorchid one had severe $(<10 \mathrm{millions} / \mathrm{ml})$ and nine had moderate oligospermia. Only three of the 14 bilaterally cryptorchid patients had normal sperm counts ( $>40$ millions $/ \mathrm{ml}$ ); six of the remainder had

TABLE I-Mean testicular volume $( \pm S D)$ in surgically treated cryptorchidism

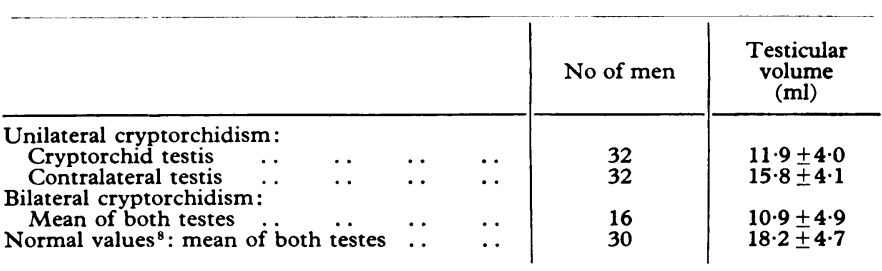




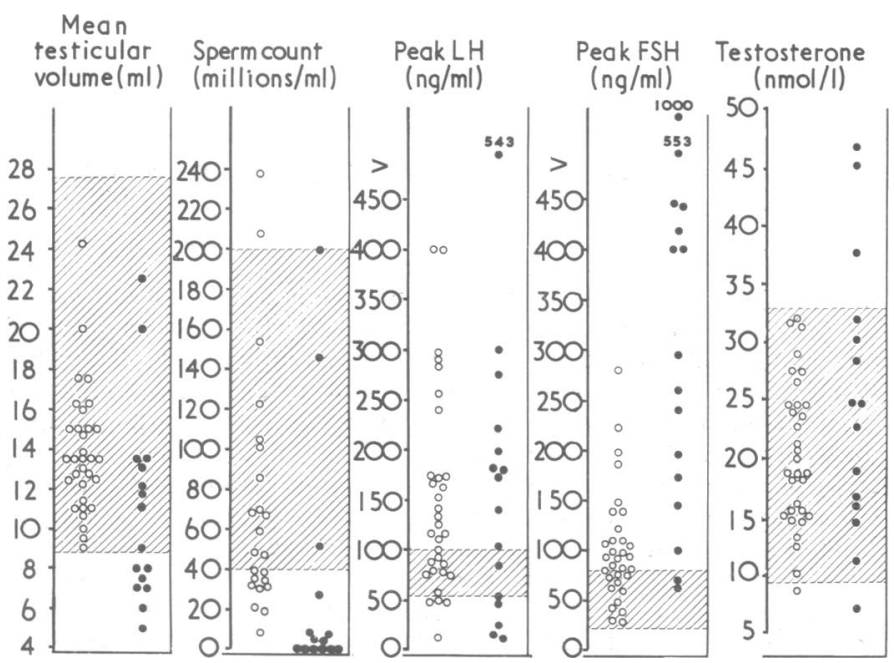

Results of endocrine studies in men with surgically treated unilateral $(\mathrm{O})$ and bilateral (O) cryptorchidism. Shaded areas represent normal ranges (mean $\pm 2 S D$ ) for mean testicular volume and hormone values. One patient who had had bilateral cryptorchidism did not have his blood examined for testosterone.

Conversion: SI to traditional units-Testosterone: $1 \mathrm{nmol} / 1 \approx 28.8 \mathrm{ng}$ | $100 \mathrm{ml}$.

azoospermia, four had severe oligospermia, and one had moderate oligospermia. Calculated values of total sperm count did not appreciably change the data on sperm concentration. Low sperm concentrations were usually coupled with small volumes of seminal fluid, decreased sperm motility, and a high rate of abnormal sperm morphology.

The results of the LH-RH test (see figure) showed that peak LH concentrations were normal or slightly below normal in 12 out of 32 men who had had unilateral cryptorchidism, but in only three of the 16 men who had had bilateral cryptorchidism. In four cases (three bilateral) peak LH was considerably below and in 29 (10 bilateral) above the normal range. Peak FSH concentrations were normal in 14 patients who had had unilateral and in two who had had bilateral cryptorchidism; peak FSH levels were higher than normal in 32 (14 bilateral) patients, 12 of whom (10 bilateral) showed greatly increased values ( $>200 \mathrm{ng} / \mathrm{ml}$ ).

Plasma testosterone was within the normal range for healthy normal men (see figure) except for two subnormal and three moderately elevated values. The figures for unilateral cases (mean $\pm \mathrm{SD}$ : $20 \cdot 8 \pm 6 \cdot 4 \mathrm{nmol}(600 \pm 184 \mathrm{ng} / 100 \mathrm{ml}))$ and bilateral cases $(25 \cdot 3 \pm 11.9$ $\mathrm{nmol}(730 \pm 343 \mathrm{ng} / 100 \mathrm{ml}))$ were not significantly different.

Statistics-Pairs of all studied indices of gonadal function shown in the figure were correlated. In those who had had unilateral cryptorchidism there were no significant correlations. For those who had had bilateral cryptorchidism, however, highly significant correlations $(\mathrm{P}<0.001)$ were found for mean testicular volume and sperm count $(r=0.88)$ and for peak FSH and peak LH $(r=0.83)$. Peak LH correlated with sperm count $(r=-0.59)$ and with mean testicular volume $(r=-0.53)$ at the $5 \%$ level. Although the peak FSH correlated poorly with testicular volume in those who had had bilateral cryptorchidism ( $r=-0.46$, not significant) as well as in those who had had unilateral cryptorchidism $(r=-0 \cdot 26$, not significant), they correlated well in all patients $(r=-0.49, P<0.001)$.

\section{Discussion}

Only two men who had been operated on for cryptorchidism presented normal findings on all our investigations. A summary of our findings (table II) shows that the men fell into the following groups:

Compensated hypergonadotrophic hypogonadism-This was defined by raised gonadotrophin concentrations but a normal sperm count. It was present in half the patients who had had unilateral cryptorchidism but in only one man who had had bilateral cryptorchidism, in whom an isolated increase of $\mathrm{LH}$ was noted.
TABLE II-Summary of results in men with surgically treated cryptorchidism

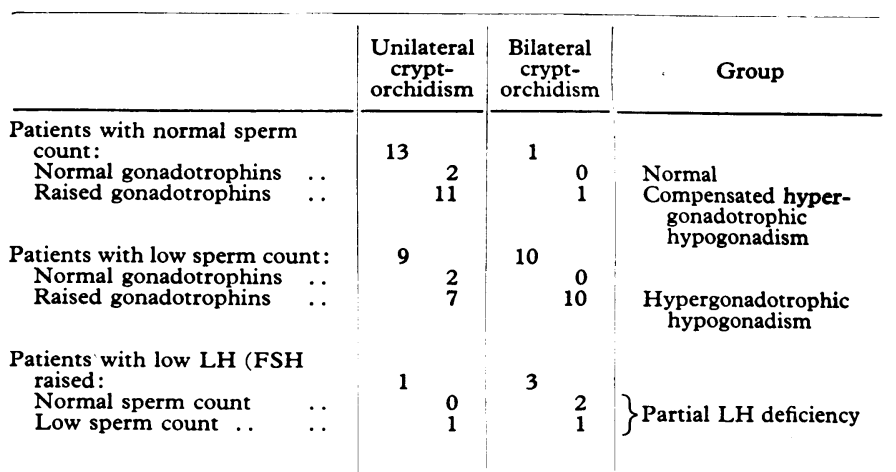

Hypergonadotrophic hypogonadism with high gonadotrophin levels and a low sperm count was found in most men who had had bilateral cryptorchidism and in a third of those who had been unilaterally cryptorchid.

Partial $L H$ deficiency may be a causative factor of infertility in a few patients with low LH levels. In these patients androgen production and clinical androgen effects were normal and two of the three men who had had bilateral cryptorchidism even had normal testicular volumes and sperm counts.

Our findings indicate that mean testicular volume in those who have had bilateral cryptorchidism is a good index of reproductive function because it is strongly correlated with sperm count.

Our sperm count data are similar to those of Hansen's ${ }^{1}$ and to the later findings of Scott, ${ }^{2}$ Bergstrand and Qvist, ${ }^{3}$ Maier and Spann, ${ }^{4}$ and Albescú et al. ${ }^{5}$ Hansen's analysis of seminal fluid showed that all patients with untreated bilateral cryptorchidism were later found to be infertile, but azoospermia was also found in 14 out of 25 surgically treated cases. In unilateral cryptorchidism the results of sperm counts were no different in treated and untreated cases. The age at operation was not indicated. Slightly better results were reported by MacCollum, ${ }^{9}$ Brunet et al, ${ }^{10}$ Hortling et $a l,{ }^{11}$ and Bramble et al. ${ }^{12}$ Albescú et $a l^{5}$ emphasised that infertility may be observed in some patients in whom testicular descent had been induced by human chorionic gonadotrophin. This has recently been confirmed by Richter et al. ${ }^{13}$ Ludwig and Potempa ${ }^{14}$ suggest that fertility depends on the age at operation. They noted a higher incidence of infertility in men who had had bilateral cryptorchidism when surgery was performed late in childhood.

Our LH and FSH results agree with those of several others. ${ }^{12}$ 13 $^{15-17}$ Basal LH levels were variable. Peak LH concentrations after LH-RH were usually normal or increased. In the large series of Koch $e t a^{17}$ the incidence of low peak LH levels after LH-RH was $6.2 \%$, which is close to the $8.8 \%$ that we observed. FSH concentrations were often found to be normal or increased, ${ }^{12131516}$ as in our series, while low basal FSH levels were reported only in four patients with treated unilateral cryptorchidism. ${ }^{16}$ Although high peak FSH levels after LH-RH are usually associated with high peak LH levels, they may also occur in the presence of normal peak $\mathrm{LH}$ values, as observed by Bramble et $a l^{15}$ and by us. Because of this dissociation Bramble et $a l^{15}$ supported the speculation that FSH secretion may be specifically controlled at the pituitary level by an "inhibin," which, as has been suggested, may be produced by the germinal epithelium.

Plasma testosterone concentrations and clinical androgen effects were normal in most of our patients, which confirms previous findings. ${ }^{1718}$ The few moderately abnormal testosterone values recorded in our patients do not indicate Leydig cell hyperactivity or dysfunction.

Histological testicular changes in cryptorchidism are great even before puberty. They consist primarily of a maturation arrest of the germinal epithelium with impaired spermatogenesis 
and interstitial fibrosis. ${ }^{719-21}$ The changes seem to be more severe in bilateral cryptorchidism. ${ }^{7}$ In unilateral cryptorchidism the scrotal testis may show similar histological changes. ${ }^{6}{ }^{7}$ The common finding of raised gonadotrophin levels indicates that cryptorchidism is generally a primary testicular disease. Conversely, the high incidence of cryptorchidism in those with gonadotrophin deficiency ${ }^{22}$ and our patients with low peak LH values suggest that in a minority the undescended testis may also be a secondary manifestation of hypothalamo-pituitary dysfunction.

This work was supported by the Schweizerischer Nationalfonds zur Förderung der wissenschaftlichen Forschung, grants No KF 1, 3.422.074, 3.405.074.

\section{References}

${ }^{1}$ Hansen, T S, Proceedings of the Royal Society of Medicine, 1959, 42, 645.

2 Scott, L S, Proceedings of the Royal Society of Medicine, 1962, 55, 1047.

${ }^{3}$ Bergstrand, C G, and Qvist, O, in Long-term Observations of Chronic Diseases, ed F Linneweh, p 254. Berlin, Springer, 1960.
${ }^{4}$ Maier, W, and Spann, W, Deutsche medizinische Wochenschrift, 1962, 87, 1697.

5 Albescú, J C, Bergadá, C, and Cullen, M, Fertility and Sterility, 1971, 22, 829.

${ }^{6}$ Hecker, W C, and Hienz, H A, fournal of Pediatric Surgery, 1967, $2,513$.

' Salle, B, Hedinger, C, and Nicole, R, Acta Endocrinologica (København), $1968,58,67$.

Zachmann, M, et al, Helvetica Paediatrica Acta, 1974, 29, 61.

9 MacCollum, D W, Archives of Surgery, 1953, 31, 290.

${ }^{10}$ Brunet, J, De Mowbray, R R, and Bishop, P M F, British Medical fournal, 1958, 1, 1367.

${ }^{11}$ Hortling, H, et al, fournal of Clinical Endocrinology, 1967, 27, 120

${ }^{12}$ Bramble, F J, et al, Lancet, 1974, 2, 311.

${ }^{13}$ Richter, W, et al, Klinische Wochenschrift, 1976, 54, 467.

${ }^{14}$ Ludwig, G, and Potempa, J, Deutsch medizinische Wochenschrift, 1975, 100,680 .

${ }^{15}$ Bramble, F J, et al, Clinical Endocrinology, 1975, 4, 443.

${ }^{16}$ Epstein, M T, Atkinson, P M, and Rippon, A E, fournal of Endocrinology, 1975, 65, 11 P.

${ }^{17}$ Koch, H, et al, Deutsche medizinische Wochenschrift, 1975, 100, 683.

${ }_{18}$ Canlorbe, P, et al, Archives Francaises de Pédiatrie, 1974, 31, 145.

19 Sohval, A R, American fournal of Medicine, 1954, 16, 346.

${ }^{20}$ Mancini, R E, et al, fournal of Clinical Endocrinology, 1965, 25, 927.

${ }^{21}$ Dougall, A J, Maclean, N, and Wilkinson, A W, Lancet, 1974, 1, 771.

${ }^{22}$ Santen, R J, and Paulsen, C A, fournal of Clinical Endocrinology, 1973, 36, 47.

\title{
Weak autoantibody reactions to antigens other than sperm after vasectomy
}

\author{
J D MATHEWS， D C G SKEGG， M P VESSEY， M KONICE， E J HOLBOROW， J GUILLEBAUD
}

British Medical fournal, 1976, 2, 1359-1360

\section{Summary}

Autoantibody activity against various antigens was measured by indirect immunofluorescence in 97 men about to undergo vasecto my and 170 men who had undergone the operation up to six years earlier. There was a significantly higher prevalence of weakly positive autoantibody reactions among those who had undergone vasectomy. There was, however, no evidence that vasectomy could induce stronger autoantibody reactions such as those associated with autoimmune disease.

\section{Introduction}

Antibodies to sperm are often produced after vasectomy, ${ }^{1-3}$ although there is no evidence that they affect health. ${ }^{1}$ We

Department of the Regius Professor of Medicine, University of Oxford, Oxford

J D MATHEWS, MD, FRACP, research fellow (present address: University Department of Medicine, Royal Melbourne Hospital, 3050 Victoria, Australia)

D C G SKEGG, BMEDSC, MB, lecturer in epidemiology

Department of Social and Community Medicine, University of Oxford, Oxford

$M$ P VESSEY, MD, FFCM, professor

MRC Rheumatism Unit, Canadian Red Cross Hospital, Taplow, Berks

$M$ KONICE, MD, research fellow

E J HOLBOROW, MD, MRCPATH, director

Nuffield Department of Obstetrics and Gynaecology, University of Oxford, Oxford

J GUILLEBAUD, FRCS ED, MRCOG, research fellow conducted a study to determine whether the prevalence of autoantibodies to antigens other than sperm is also increased after vasectomy.

\section{Methods}

As previously reported, ${ }^{4} 288$ men were examined: 100 before vasectomy and 188 at varying intervals up to six years after the operation. Blood was taken and serum stored at $-20^{\circ} \mathrm{C}$. Samples were available from 97 men in the prevasectomy group and 170 men after operation.

Autoantibody activity was measured by indirect immunofluorescence using compound tissue blocks of rat liver, kidney, and stomach as substrates. ${ }^{5}$ Coded sera were assayed blind at a dilution of $1 / 10$ using polyspecific fluorescent antiglobulin reagents. The strength of immunofluorescence was graded from 0 (negative) to 4 (strongly positive) for each of the following antigens: nuclei in liver, tubules and brush border in kidney, and parietal cells in stomach. Smooth muscle antibody and reticulin antibody (including atypical reticulin patterns) were graded according to established criteria..$^{5-7}$ Mitochondrial, bile duct, adventitial, and Kupffer cell staining were graded as 0 (negative) or 1 (positive).

\section{Results}

At least one autoantibody reaction was observed in 127 of the 170 men who had undergone vasectomy $(74.7 \%)$ compared with 58 of the 97 men seen before operation $(59.8 \%)$. This difference was statistically significant $\left(\chi_{1}^{2}=5.77 ; \mathrm{P}<0.02\right)$. Men who had had vasectomies also tended to have more positive autoantibody reactions (table I).

TABLE I-Proportions of men with and without vasectomies who had different numbers of positive autoantibody reactions. Results are numbers (and percentages)

\begin{tabular}{|c|c|c|c|c|c|}
\hline No of positive reactions: & 0 & 1 & 2 & 3 & $\geqslant 4$ \\
\hline $\begin{array}{l}\text { Before vasectomy }(n=97) \\
\text { After vasectomy }(n=170)\end{array}$ & $\begin{array}{l}39(40 \cdot 2) \\
43(25 \cdot 3)\end{array}$ & $\left|\begin{array}{l}27(27 \cdot 8) \\
47(27 \cdot 6)\end{array}\right|$ & $\begin{array}{l}18(18.6) \\
44(25.9)\end{array}$ & $\begin{array}{c}9(9 \cdot 3) \\
29(17 \cdot 1)\end{array}$ & $\begin{array}{l}4(4 \cdot 1) \\
7(4 \cdot 1)\end{array}$ \\
\hline
\end{tabular}

$\chi_{1}^{2}$ for trend $=6.44 ; P<0.02$ 